\title{
Clinico-Endoscopic Profile and Outcome of Corrosive Ingestion: A Single Centre Experience from a Tertiary Care Hospital in Southern India
}

\author{
Vijay Kumar TR, Anil Kumar G, Nandeesh HP, Deepak Suvarna, Aradya HV, Anurag Lavekar, Rithesh Reddy
}

Department of Medical Gastroenterology, JSS Medical College and Hospital, JSS Academy of Higher Education \& Research

\section{ABSTRACT}

Background: Corrosive substances are common household substances that can be ingested either accidentally or with suicidal intent. Contents of the corrosives range from acid to alkali in varied concentrations. Corrosive ingestion represents serious problems with varied presentation and long term complications. Present study aims to explore the clinical-endoscopic profile and outcome of corrosive ingestion.

Methods: We analysed clinical, endoscopy characteristics, outcome and complications of all consecutive patients presented with corrosive ingestion from August 2016 to August 2018. Results: A total of 36 patients were included over a period of 2 years. There were 20 males $(55.6 \%)$. Mean age of presentation was 35.6 years (3-65 years). Paediatric age group patients were $5(13.8 \%)$. Common symptom was vomiting in 21 patients $(58.3 \%)$. Common mode of ingestion was accidental (66.7\%). Acid ingestion was seen in 27 patients (75\%). Mean ingestion of corrosive to oesophagogastroduodenoscopy (OGD) time was 31.33 hours. Twenty $(55.6 \%)$ patients with corrosive injury had Zargar class III mucosal injury. On follow up, $55 \%$ of patients with type III mucosal injury developed Gl complications like oesophageal stricture and gastric outlet obstruction (G00).

Conclusions: In our study, acid ingestion is seen in two third of patients. Most common mode of ingestion was accidental. Paediatric corrosive ingestion is 13.8\%. Half of patients had type III Zargar mucosal injury. 55\% of patients with type III mucosal injury developed GI complications like oesophageal stricture and G00. Zargar type III mucosal injury is associated more with acid ingestion compared to alkali. Endoscopy is safe procedure upto 3 days with no procedure related complications.

Key words: corrosive esophageal injury, upper Gl endoscopy, esophageal stricture

\section{INTRODUCTION}

Corrosive ingestion is a grave public health problem across the globe (1). It is more common in the developing countries, but still seen in developed countries. The word 'corrosive' is derived from the Latin verb corrodere, which means 'to gnaw away', indicating how these substances seem to
Corresponding author:

Dr. Vijay Kumar T R, Asst Prof. Department of Medical Gastroenterology

E-mail: drvijaytr@yahoo.com 
'gnaw' their way through flesh or other material.

Corrosive ingestion is a medical emergency and shows diverse clinical presentations. Its clinical course is exceedingly complex. Corrosive ingestions may result in extensive injury to the lips, oral cavity, pharynx, and the upper airway. The examples of most commonly used corrosive materials include sulphuric acid, nitric acid, phosphoric acid, hydrochloric acid, oxalic acid, sodium hydroxide, potassium hydroxide and bleaches (2). These corrosive materials are found in drain cleaners, various cleaning agents, hair relaxers, dishwasher detergents, and disk batteries (2). It may cause massive haemorrhage, gastrointestinal tract perforation, aortoenteric/gastro-colic fistulae, tracheal stenosis, and the tracheoesophageal fistula (3). They can cause oesophageal perforation, stricture formation and later may lead to the development of oesophageal carcinoma (3). The cumulative rate of these various complications is estimated up to $23.61-89.3 \%(4,5)$. Endoscopy is important diagnostic test for prognosis and management of corrosive ingested patients. OGD can be done between 48 and 72 hours of corrosive ingestion, due to high risk of perforation OGD not recommended between 5 and 15 days after corrosive ingestion. Most commonly used endoscopic classification for corrosive mucosal injury is Zargar's system [class I- oedema and erythema, class IIA- haemorrhage, erosions, blisters, ulcers with exudates, class IIBcircumferential ulcerations, class III- multiple deep ulcers with brown, black, or grey discolouration, class IV- perforation]. The extent of corrosive injuries is mainly dependant upon the exposure time, nature, amount and concentration of the corrosive agent (6). Generally, acids with $\mathrm{pH}$ less than 3 or bases with $\mathrm{pH}$ greater than 11 are notorious for causing corrosive injury of tissues (1).

Recent medical literature reveals that corrosive ingestion is seen in every age group. Ingestion may be either deliberately with suicidal intent or accidental. In developing countries, the incidence of corrosive ingestion is significantly higher and in most cases remains unreported.

A study by World Health Organisation (WHO) stated that in past 17 years, only 37 papers were published concerning corrosive ingestion in low- and lower-middle income countries. Out of these 37, only eight papers focussed the specific epidemiology of corrosive ingestion (7). Our study wanted to analyse clinical endoscopic profile and outcome of corrosive ingestion.

\section{MATERIALS AND METHODS}

This descriptive, prospective, observational study was conducted at the Department of Medical gastroenterology, JSSH, Mysuru, and Karnataka. The duration of the study was from Aug 2016 to Aug 2018. All the cases with the primary diagnosis of corrosive ingestion were included in the study. The inclusion criteria were patient with corrosive ingestion, hospitalised in the department of Medical gastroenterology. Only new cases were included, follow-up cases and cases with ingestion of substances other than corrosives were not included in the study. All these cases were evaluated by detailed history and thorough physical examination. OGD was done to all patients after stabilisation. The post corrosive mucosal damage was classified according to ZARGAR's classification system for caustic injury. According to needs of patients, various laboratory investigations and imaging studies were performed for the further evaluation. Data was collected for the measurement of different variables such as age, gender, type and the cause of ingestion (intentional or accidental), prominent symptoms. Patient was asked for follow-up after 8 weeks of corrosive ingestion for assessment of complications. This information was recorded on a specifically designed Performa. All statistical analysis data was entered into Microsoft Excel (Windows 7; Version 2007) and analyses were done using the Statistical Package for Social Sciences (SPSS) for Windows software (version 22.0; SPSS Inc, Chicago). Descriptive statistics such as mean and standard deviation (SD) for continuous variables, frequencies and percentages were calculated for categorical Variables were determined. Bar charts and Pie charts were used for visual representation of the analysed data.

\section{RESULTS}

The current study comprised of 36 cases. There were 20 males (55.6\%) and 16 female patients (44.4\%). Age ranged from 3 to 65 years (mean 35.6 years). Paediatric age group patients were 5 (13.8\%). Most common mode of ingestion was accidental ingestion seen in two third of patients (66.7\%). Acid ingestion was seen in 27 patients (75\%) were as alkaline ingestion seen in 9 patients (25\%). Most common presenting symptom was vomiting, seen in 21 patients (58.3\%), followed by dysphagia in 14 patients (38.9\%) and burning sensation in throat 14 patients (38.9\%). Mean ingestion of corrosive to OGD time was 31.33 hours (8-72hours). In this study Twenty (55.6\%) patients with 
corrosive injury had Zargar class III mucosal injury, of which 18 were due to acid ingestion. In this study on follow up, 11 patients developed GI complications like oesophageal stricture in 5 patients (3.5\%) and $\mathrm{GOO}$ in 6 patients (16.7\%). Amongst them $\mathrm{FJ}$ was done on 6 (16.7\%) patients. Average length of hospital stay was 5 days (1-16 days). In this study acid ingestion was statistically significant for complications rather than alkaline.

Table 1 - Distribution of study subjects according to the demographic characteristics $(\mathrm{N}=36)$

\begin{tabular}{lcc}
\hline Variable & Frequency & Percent \\
\hline Age (in Years) & \multicolumn{3}{c}{} \\
$\leq 20$ & 6 & 16.7 \\
$21-30$ & 6 & 30.6 \\
$31-40$ & 4 & 16.7 \\
$41-50$ & 7 & 11.1 \\
$51-60$ & 2 & 19.4 \\
$>60$ & \multicolumn{3}{c}{$35.64(16.76)$} \\
\hdashline Mean (SD) & $3-65$ & 5.6 \\
\hline Range & \multicolumn{3}{c}{} \\
\hdashline Gender & 20 & 55.6 \\
Male & 16 & 44.4 \\
Female &
\end{tabular}

Table 2 - Distribution of study subjects according to the OGD findings $(\mathrm{N}=36)$

\begin{tabular}{lcc}
\hline $\begin{array}{l}\text { OGD Findings } \\
\text { (Zargar Class) }\end{array}$ & Frequency & Percent \\
\hline 0 & 3 & 8.3 \\
\hline 1 & 8 & 22.2 \\
\hline $2 \mathrm{~A}$ & 4 & 11.1 \\
\hline $2 \mathrm{~B}$ & 1 & 2.8 \\
\hline 3 & 20 & 55.6 \\
\hline
\end{tabular}

Table 3 - Distribution of Study Subjects according to Mode of Ingestion, Type of Corrosive and Ingestion to OGD Time $(\mathrm{N}=36)$

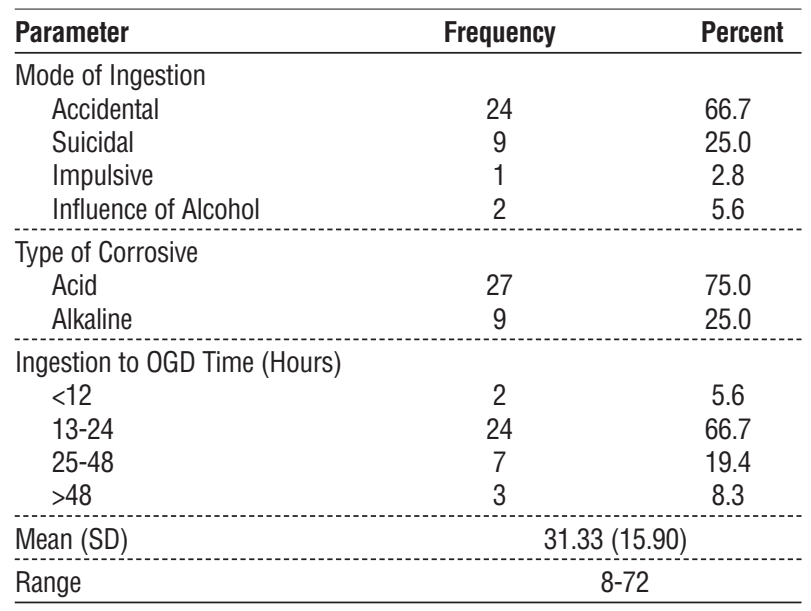

Table 4 - Distribution of Study Subjects according to Complications and Comorbidities $(\mathrm{N}=36)$

\begin{tabular}{lcc}
\hline Complications & Frequency & Percent \\
\hline GI Complications & & \\
$\quad$ Oesophageal Stricture & 5 & 13.9 \\
G00 & 6 & 16.7 \\
\hdashline Systemic Complications & 2 & \\
AKI & 1 & 5.6 \\
ARDS & & 2.8 \\
\hline Comorbidities & 3 & \\
DM & 2 & 5.3 \\
HTN & 1 & 2.8 \\
Hypothyroidism & 1 & 2.8 \\
Kochs & 1 & 2.8 \\
Primi &
\end{tabular}

Table 5 - Distribution of Study Subjects according to Length of Stay $(\mathrm{N}=36)$

\begin{tabular}{lcc}
\hline $\begin{array}{l}\text { Length of Stay } \\
\text { (in Days) }\end{array}$ & Frequency & Percent \\
\hline $1-3$ & 8 & 22.2 \\
\hline $4-7$ & 23 & 63.9 \\
\hline 7 & 5 & 13.9 \\
\hline Mean (SD) & \multicolumn{2}{c}{$5.25(2.82)$} \\
\hline Range & $1-16$ \\
\hline
\end{tabular}

Table 6 - Distribution of Study Subjects according to Clinical Features $(\mathrm{N}=36)$

\begin{tabular}{lcc}
\hline Clinical Features & Frequency & Percent \\
\hline Burning Sensation & & \\
\hline in Abdomen \& Throat & 14 & 38.9 \\
\hline Throat Pain & 5 & 13.9 \\
\hline Vomiting & 21 & 58.3 \\
\hline Dysphagia & 14 & 38.9 \\
\hline Pain Abdomen & 8 & 22.2 \\
\hline Gl Bleed & 4 & 11.1 \\
\hline
\end{tabular}

Table 7 - Association between Type of Corrosive and Complications $(\mathrm{N}=36)$

\begin{tabular}{lccc}
\hline Complications & \multicolumn{2}{c}{ Type of Corrosive } & P Value \\
\hline & $\begin{array}{c}\text { Acid } \\
(\mathbf{n}=27) \\
\mathbf{n}(\%)\end{array}$ & $\begin{array}{c}\text { Alkaline } \\
(\mathbf{n}=\mathbf{9}) \\
\mathbf{n}(\%)\end{array}$ & \\
\hline$-3(18.5)$ & 0 & 0.164 \\
\hline Oesophageal Stricture & 5 & 0 \\
\hdashline G00 & $4(14.8)$ & $2(22.2)$ & 0.605 \\
\hdashline Type 3 Mucosal Injury & $18(66.7)$ & $2(22.2)$ & $0.020^{*}$ \\
\hline
\end{tabular}

Chi-Square Test, * $\mathrm{P}$ Value Significant 


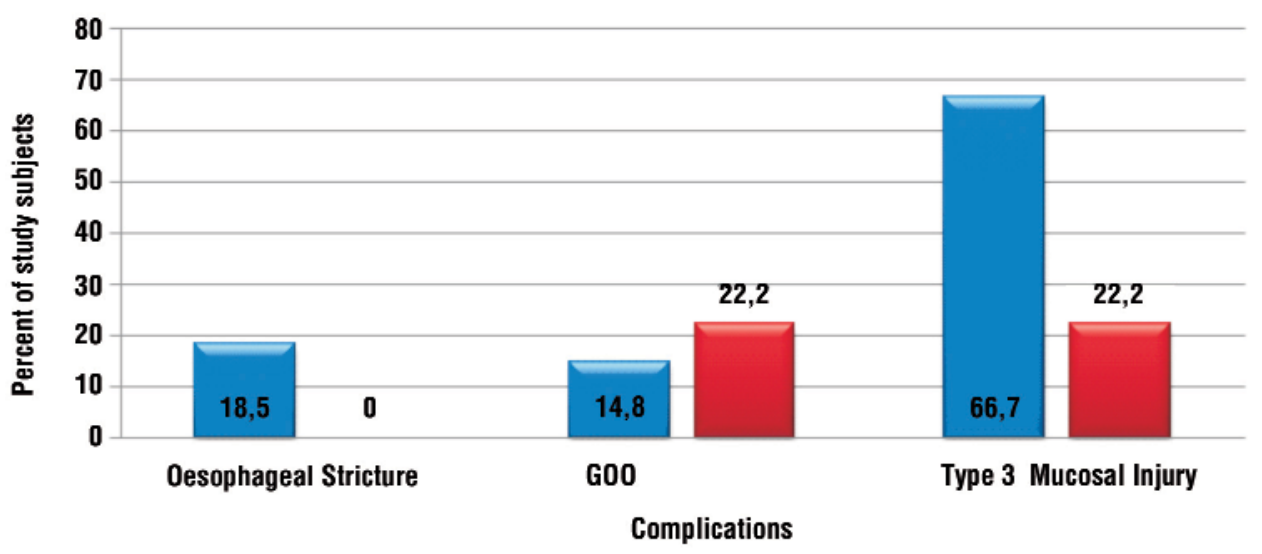

Figure 1 - Association between type of corrosive \& complications

\section{DISCUSSION}

Corrosive ingestion is associated with the potentially catastrophic presentation and long standing complications (8). Study of the epidemiology of corrosive intake is important from a preventive view point. Different studies show different demographic characteristics of corrosive ingestion patients.

In our study mean age of corrosive ingestion was 35.6 years (3-65years) age group. Paediatric age group patients were $5(13.8 \%)$. In a study by Chena et al., patients older than 40 years of age constitute $55.2 \%$ of the total sample size. While, in America, $50-80 \%$ incidences of corrosive ingestion occur in children $(7,9)$. Adedeji to a et al reports that the incidence amongst children in India and Nigeria is $15 \%$ and $25 \%$, respectively (10). These findings show that the incidence of corrosive intake varies significantly in similar age groups of different countries. Preventive measures can be taken to reduce the incidence of corrosive ingestion.

The present study shows corrosive ingestion in males is more than female population. This is in contrast to the results of a study conducted in Taiwan in which the incidence rate of corrosive intake in females was more than male.

The most common presentation of corrosive ingestion in Contini $\mathrm{S}$ a et al study is abdominal pain, vomiting, and hematemesis (11-15). In our study most common presenting symptom was vomiting, seen in 21 patients $(58.3 \%)$, followed by dysphagia in 14 patients (38.9\%) and burning sensation in throat 14 patients (38.9\%).

In our study most common mode of corrosive ingestion was accidental in $24(66.7 \%)$ cases, 9(25\%) cases were suicidal, and 2 (5.6\%) cases were under influence of alcohol and 1 (2.8\%) case under impulsive. In the Lupa $M$, Magne aet al study most common mode of corrosive ingestion was suicidal found in 30 (73.2\%) cases and only 11 (26.8\%) were accidental (1). Proper labelling and unique containers of corrosive substances and rules for availability of strong corrosive in preventing accidental ingestion of corrosive substance.

In our study acid ingestion was seen in 27 patients (75\%) were as alkaline ingestion seen in 9 patients (25\%). It is in contrast to the results of studies conducted in Western countries where alkali material accounts for most of the ingestions (2). But the findings of an Indian study conducted by Zargar aet al. are consistent with our study which reports the use of different types of acids in all cases (16). Indian data are strikingly different; the majority of ingestions are due to acids (17-19) as these are more easily available

In our study twenty (55.6\%) patients with corrosive injury had Zargar class III mucosal injury, followed by grade I eight (22.2\%) patients, grade IIA four (11.1\%) patients and grade IIB one (2.8\%) patient. Normal mucosal study was seen in $8.3 \%$ of patients. In Heng HT aet al series, more severe injuries such as grades $3 \mathrm{~b}$ and $2 \mathrm{~b}$ tend to predominate (20), whereas in most other centres, minor injuries are more common than the severe ones $(21,22)$. Severity of mucosal damage depends upon type of corrosive, amount, and concentration of corrosive ingestion. Reason for more grade III mucosal injury in our study might be referral bias.

Early endoscopy is regarded as the most appropriate measure based on which clinical decisions are made in people who have ingested corrosive substances $(16,23-$ 28). Zargar aet al performed endoscopies on 88 patients within $96 \mathrm{~h}$ following corrosive ingestion and found no complications related to the procedure (22). In our study 

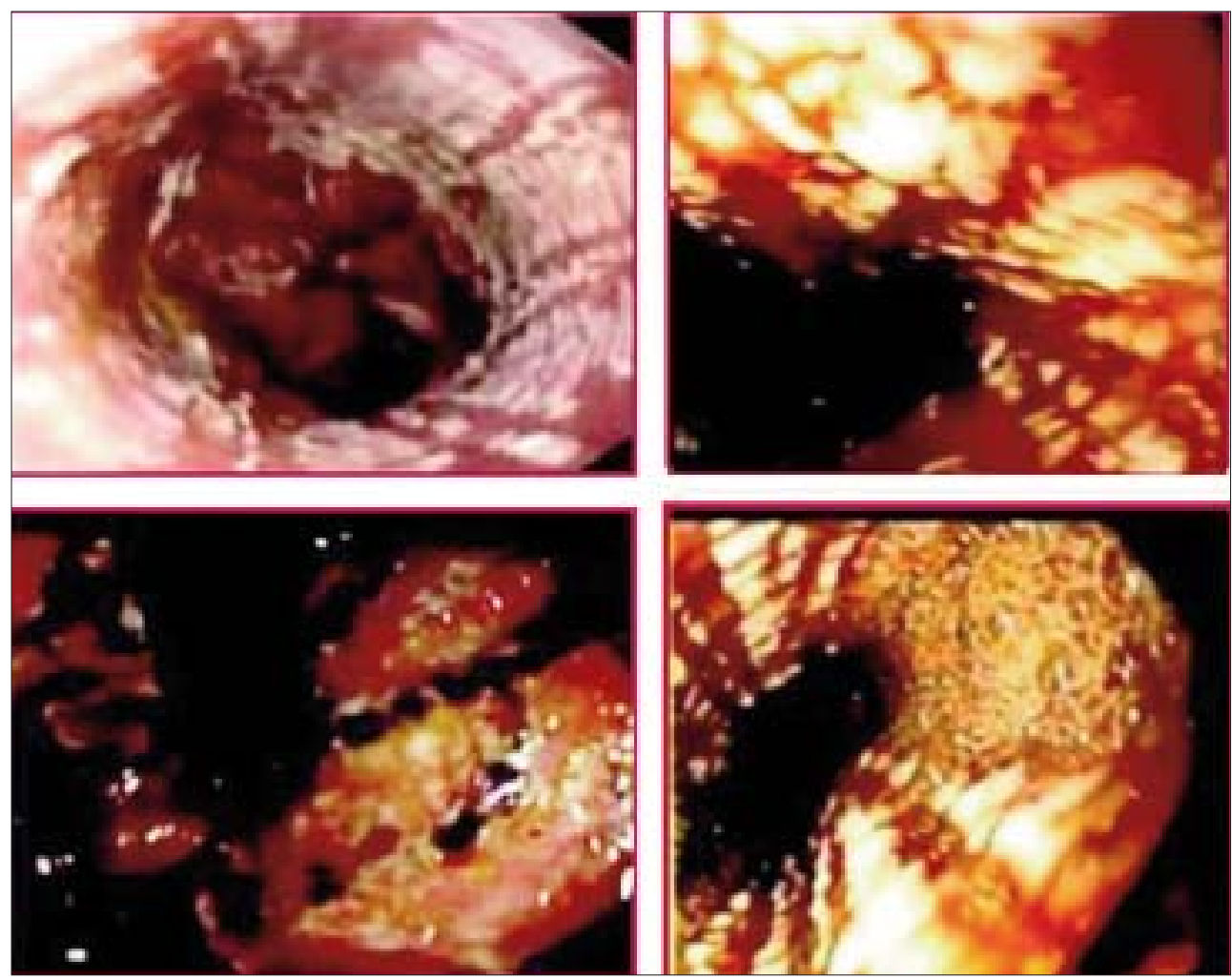

Figure 2 - Following corrosive ingestion. a, b, d - showing esophageal injury (Zargar's class II-III), c - showing gastric mucosal injury (Zargar's class II)

mean ingestion of corrosive to OGD time was 31.33 hours (8-72 hours). OGD was done as early as 8hours and up to 3 days. No procedure related complications observed.

Strictures usually develop within 8 weeks after the ingestion, but it can happen as early as after 3 weeks or as late as after 1 year. Stricture formation with grade IIB and a grade III oesophageal injury is $71 \% 22$ and $100 \%$, respectively (29-30). In our study $55 \%$ of patients with type III mucosal injury developed GI complications like oesophageal stricture and gastric outlet obstruction (GOO). Reason for lesser percentage of stricture formation in our study might be due to subjective grading of zargar classifications. Obviously, ingestion of powerful caustic substances (e.g., sodium hydroxide) is followed by severe, long-standing strictures and dramatically altered oesophageal motility (31). In our study we observed acid ingestion caused both oesophageal stricture (18.5\%) and GOO (14.8\%) where as alkaline ingestion caused GOO in $22 \%$ of patients. Difference noted in our study might be due to dilution of the corrosive substances or mixing of substances.

Compared with alkali, ingestion of a strong acid may be associated with a higher incidence of systemic complications, such as renal failure, liver dysfunction, disseminated intravascular coagulation and haemolysis $(32,38)$. In our study, we had two cases of (5.6\%) AKI and one case (2.8\%) of ARDS which is seen more with acid ingestion patients.

Patients with grade IIIB and IV have high early mortality rate up to $65 \%$ (34-36) the degree of oesophageal injury at endoscopy is a predictor of systemic complication and death with a 9-fold increase in morbidity and mortality for every increased injury grade (27). We observed that acid ingestion is associated with type III mucosal injury than alkaline $P$ value was significant $(0.02)$. The mean hospital stay was 11.8 days \pm 11.1 in our study. While the shortest hospitals stay was one day. In our study majority of Grade III oesophageal injury patients 20 cases (55.6\%) were had longest hospital stay. In our study there is no mortality amongst admitted patients.

Limitation our study, we failed to gather information about the exact names and chemical constituents of various corrosive substances. We observed quite improper and inadequate labelling system on the containers of corrosive products. 


\section{CONCLUSIONS}

In our study, acid ingestion is more common being seen in two third of patients. Most common mode of ingestion was accidental. Mean age of presentation was 35.6 years (3-65 year). Paediatric corrosive ingestion is $13.8 \%$. Half of patients had type III Zargar mucosal injury. 55\% of patients with type III mucosal injury developed GI complications like oesophageal stricture and GOO. Zargar type III mucosal injury is associated more with acid ingestion compared to alkali. OGD is safe procedure for assessment of mucosal injury upto 3 days of corrosive ingestion.

Awareness about the debilitating effects of corrosive ingestion to population and enforcing regulations for the manufacturers of household cleaning products can significantly reduce the incidence of corrosive injury.

\section{Conflict of Interest}

No conflict of interest/no disclaimers.

\section{REFERENCES}

1. Lupa M, Magne J, Guarisco JL, Amedee R. Update on the diagnosis and treatment of caustic ingestion. Ochsner J. 2009, 9:54-59

2. Contini S, Scarpignato C. Caustic injury of the upper gastrointestinal tract: a comprehensive review. World J Gastroenterol. 2013, 19:3918-30

3. Mamede RC, De Mello Filho FV. Treatment of caustic ingestion: an analysis of 239 cases . Diss Oesophagus. 2002, 15:210-213.

4. Chibishev AA, Simonovska N, Bozinovska C, Pereska Z, Smokovsk I, Glasnovic M: Respiratory complications from acute corrosive poisonings in adults. Mater Sociomed. 2014, 26:80-83.

5. Mamede RC, Mello Filho FV. Ingestion of caustic substances and its complications. Sao Paulo Moed J. 2001, 119:10-15.

6. Vezakis Al, Pantiora EV, Kontis EA. Clinical spectrum and management of caustic ingestion: a case series presenting three opposing outcomes. Am J Case Rep. 2016, 17:340-46.

7. McKenzie LB, Ahir N, Stolz U, Nelson NG. Household cleaning product-related injuries treated in US emergency departments in 1990-2006. Paediatrics. 2010, 126:509-16.

8. Park KS. Evaluation and management of caustic injuries from ingestion of acid or alkaline substances. Clin Endosc. 2014, 47:301-07.

9. Rafeey M, Ghojazadeh M, Sheikhi S, Vahedi L. Caustic ingestion in children: a systematic review and meta-analysis. J Caring Sci. 2016 , 5:251-65.

10. Adedeji TO, Tobih JE, Olaosun AO, Sogebi OA. Corrosive oesophageal injuries: a preventable menace. Pan Afr Moed J. 2013, 15:1-5.

11. Vezakis Al, Pantiora EV, Kontis EA .: Clinical spectrum and management of caustic ingestion: a case series presenting three opposing outcomes. Am J Case Rep. 2016, 17:340- 46.

12. Turner A, Robinson P: Respiratory and gastrointestinal complications of caustic ingestion in children. Emerg Moed J. 2005, 22:359-61.

13. Contini S . Upper gastrointestinal caustic lesions July 7, 2013,19:25
14. Contini S, Scarpignato C. Caustic injury of the upper gastrointestinal tract: a comprehensive review. World J Gastroenterol 2013; 19: 3918-30.

15. Park KS. Evaluation and management of caustic injuries from ingestion of Acid or alkaline substances. Clin Endosc 2014; 47: 301-07.

16. Zargar SA, Kochhar R, Mehta S, Mehta SK. The role of fiberoptic endoscopy in the management of corrosive ingestion and modified endoscopic classification of burns. Gastrointest Endosc.1991, 37:165-69

17. Lahoti $\mathrm{D}$, Broor SL. Corrosive injury to the upper gastrointestinal tract. Indian J Gastroenterol 1993;12:135-41.

18. Nagi B, Kochhar R, Thapa BR, Singh K. Radiological spectrum of late sequelae of corrosive injury to upper gastrointestinal tract. A pictorial review. Acta Radiol 2004:45:7-12

19. Ananthakrishnan N, Parthasarathy G, Kate V. Chronic corrosive injuries of the stomach-a single unit experience of 109 patients over thirty years. World J Surg 2010:34:758-6418.

20. Cheng HT, Cheng CL, Lin CH, Tang JH, Chu YY, Liu NJ, et al. Caustic ingestion in adults: The role of endoscopic classification in predicting outcome. BMC Gastroenterol 2008;25:8-31.

21. Baskin D, Urganci N, Abbasoglu L, Alkim C, Yalcin M, Karadag C, et al. A standardised protocol for the acute management of corrosive ingestion in children. Pediatr Surg Int 2004;20:824-8.

22. Dođan Y, Erkan T, Cokuðrab FC, Kutlu T. Caustic gastroesophageal lesions in childhood: An analysis of 473 cases. Clin Pediatr (Phila) 2006:45:435-8

23. Gumaste VV, Dave PB. Ingestion of corrosive substances by adults. Am J Gastroenterol 1992; 87: 1-5.

24. Maull KI, Scher LA, Greenfield LJ. Surgical implications of acid ingestion. Surg Gynaecol Obstet 1979; 148: 895-98

25. Di Costanzo J, Noirclerc M, Jouglard J, Escoffier JM, Cano N, Martin J, Gauthier A. New therapeutic approach to corrosive burns of the upper gastrointestinal tract. Gut 1980; 21: 370-75.

26. Hawkins DB, Demeter MJ, Barnett TE. Caustic ingestion: controversies in management. A review of 214 cases. Laryngoscope 1980; 90: 98-109

27. Tekant G, Eroğlu E, Erdoğan E, Yeşildağ E, Amir H, Büyükünal C, aet al. Corrosive injury-induced gastric outlet obstruction: a changing spectrum of agents and treatment. J Pediatr Surg 2001; 36: 1004-07

28. Ramasamy K, Gumaste VV. Corrosive ingestion in adults. J Clin Gastroenterol 2003; 37: 119-24.

29. Baskin D, Urganci N, Abbasoğlu L, Alkim C, Yalçin M, Karadağ C aet al. A standardised protocol for the acute management of corrosive ingestion in children. Pediatr Surg Int 2004: 20: 824-28.

30. Kay M, Wyllie R. Caustic ingestions in children. Curr Opin Pediatr 2009; 21: 651-54.

31. Genç A, Mutaf 0 . esophageal motility changes in acute and late periods of caustic oesophageal burns and their relation to prognosis in children. J Pediatr Surg 2002; 37: 1526-28.

32. Cheng HT, Cheng $\mathrm{CL}$, Lin $\mathrm{CH}$, Tang JH, Chu YY, Liu NJ, aet al. Caustic ingestion in adults: The role of endoscopic classification in predicting outcome. BMC Gastroenterol 2008;25:8-31.

33. Poley JW, Steyerberg EW, Kuipers EJ, Dees J, Hartmans R, Tilanus HW, aet al. Ingestion of acid and alkaline agents: outcome and prognostic value of early upper endoscopy. Gastrointest Endosc 2004; 60: 372-77

34. Chiu HM, Lin JT, Huang SP, Chen CH, Yang CS, Wang HP et al. Prediction of bleeding and stricture formation after corrosive ingestion by EUS concurrent with upper endoscopy. Gastrointest Endosc 2004;60:827-33.

35. Kay M, Wyllie R. Caustic ingestions in children. Curr Opin Pediatr 2009;21:6514

36. Fulton JA, Hoffman RS. Steroids in second degree caustic burns of the oesophagus: A systematic pooled analysis of fifty years of human data: 19562006. Clin Toxicol (Phila) 2007:45:402-8. 